\title{
Connecting with Computer Science: \\ Electronic Textile Portfolios as Ideational Identity Resources for High School Students
}

\author{
Mia S. Shaw \\ University of Pennsylvania \\ U. S. A. \\ Deborah A. Fields \\ Utah State University \\ U. S. A. \\ Yasmin B. Kafai \\ University of Pennsylvania \\ U. S. A.
}

\section{ABSTRACT: The development of student identities—-their interests in computer science, perceptions of the discipline, and sense of belonging in the field-is critical for broadening participation of underrepresented groups in computing. This paper reports on the design of portfolios in which two classes of high school students reflected on the process of making electronic textile projects. We examine how students expressed self- authorship in relation to computer science and how the use of reflective portfolios shaped students' perceptions of computer science. In the discussion we consider how reflective portfolios can serve as ideational resources for computer science identity construction.}

KEYWORDS: computer science, identity, portfolios, ideational resources, electronic textiles

\author{
Background \\ Methods \\ Findings \\ Discussion \\ Acknowledgements \\ Notes \\ References \\ Author Contact
}

Widespread national efforts are promoting computer science (CS) in K-12 education (Blikstein, 2018). Drawing upon Wenger's (1998) conceptualization of the relation between learning and identity processes within communities of practice, there is a growing recognition that equal attention needs to be paid to aspects impacting students' identities as they gain access into CS communitiestheir interests in CS, their perceptions of the discipline, and their sense of 
belonging in the field (Cheryan, Master, \& Meltzoff, 2015). The need to understand issues around identities is particularly urgent for underrepresented groups such as women and people of color (particularly African-American and Latinx people) in CS education (Margolis, Estrella, Goode, Holme, \& Nao, 2008) and in workplaces (Google, 2016) in order to increase access, deepen participation, and diversify perspectives. However, developing an identity in CS is challenging because the discipline is heavily stereotyped as being White and male (Hansen et al., 2017; Cheryan, Plaut, Handron, \& Hudson, 2013), being isolating (Diekman, Brown, Johnston, \& Clark, 2010; Yardi \& Bruckman, 2007), and requiring innate brilliance rather than persistence (Leslie, Cimpian, Meyer, \& Freeland, 2015).

In order to successfully develop their identity within such a contested space, students need to have access to what Nasir and Cooks (2009) called "ideational resources," the "ideas about oneself and one's relationship to and place in the practice and the world, as well as ideas about what is valued and what is good" ( $p$. 44). Ideational resources should accompany material (the physical artifacts) and relational resources (interpersonal connections to others) found in equity and inquiry-focused instructional approaches (Goode, Chapman \& Margolis, 2012; Nasir \& Cooks, 2009), personally-relevant artifact design (Fields, Kafai, Nakajima, Goode, \& Margolis, 2018), narrative-driven curricula (Pinkard, Erete, Martin, \& McKinney de Royston, 2017), or reflective activities in culturally-relevant computing (e.g., Eglash, Gilbert, \& Foster, 2013; Scott, Sheridan \& Clark, 2015) which can leverage students' sense of self in relation to computer science and help them situate themselves on an inbound trajectory of participation in a discipline.

In this paper we share our experience with the use of learner-generated reflective portfolios that accompanied the development of electronic textile (hereafter e-textile) projects that high school students completed in an introductory Exploring Computer Science (ECS) class (Goode, Chapman \& Margolis, 2012). Etextiles combine elements of engineering, computing, and crafting by allowing learners to connect sewable components such as lights and sensors to microcontrollers using conductive thread (Buechley, 2006). While portfolios have been extensively used as a means of assessment of academic learning by documenting computational thinking concepts and practices learned (see Chang et al., 2015; Lui, Jayathirtha, Fields, Shaw, \& Kafai, 2018), here we examine them as ideational resources for student self-authorship_places where students reflect and position themselves in relation to how they develop disciplinary identities and participate in disciplinary practices in CS. In this paper we ask how students use reflective portfolios to express their own voices and self-authorship in relation to computer science. In addition, we explore how the use of reflective portfolios shapes students' perceptions of computer science. In the discussion we consider the implications of reflective portfolios as meta-artifacts in disciplinary identity construction. 


\section{Background}

Students' identities and interests in a particular discipline develop in relation to available experiences in that discipline as well as to how they perceive, understand, and represent those experiences (Renninger, 2009). The relevance of developing students' STEM (science, technology, engineering, and math) identities has been established as a cornerstone of any effort to broaden and deepen their participation and aspirations (Bell, Van Horne, \& Cheng, 2017; Tai, Liu, Maltese, \& Fan, 2006). However, a number of factors can curtail that interest, including students' perceptions of STEM disciplines and their sense of belonging in the field. Identity is a broad concept that, from a sociocultural perspective (e.g., Wenger, 1998), includes how people act in particular situations (practice-based identities, e.g., Nasir \& Hand, 2008), how people think about themselves (selfnarratives, Sfard \& Prusak, 2005), and how other people perceive someone (others'-narratives) (Fields \& Enyedy, 2014). These conceptions of identity shift as people's participation within the setting deepens, illustrating how identity is actively constructed at the intersection of both the individual and the social world (Nasir \& Cooks, 2009; Wenger, 1998). In this paper we are primarily concerned with the aspect of identity that relates to students' self-narratives-how they consciously think about themselves in the context of CS.

Being able to author one's own disciplinary identity may be especially important in a field such as CS, a field that is well documented as historically exclusive and in which many students often struggle to develop a positive sense of self or sense of belonging (Cheryan, Plaut, Handron, \& Hudson, 2013; Yardi \& Bruckman, 2007). Within computing, stereotypes about CS from the media, people in the field, and CS environments (Cheryan, Master, \& Meltzoff, 2015) have made the development of such discipline-linked identities difficult for certain groups. Research has shown that stereotypes negatively affect how girls and students of color feel they would fit in when they perceive a mismatch between the field and their identities (Cheryan, Plaut, Davies, \& Steele, 2009). Consequently, the less that students feel a sense of belonging in CS, the less likely they are to pursue it (Good, Rattan, \& Dweck, 2012; Smith, Lewis, Hawthorne, \& Hodges, 2013). As a way to alter CS stereotypes, people need both to develop and maintain meaningful narratives related to a community or practice in order to identify with it (Ezzy, 1998), and they can do so by developing personal, academically-relevant, reflective artifacts.

\section{Ideational Resources and Artifact Authorship}

It is imperative to provide opportunities for students to reflect on, compose, and share narratives about who they are and who they are becoming in relation to CS (Varelas, Martin, \& Kane, 2012). In this context, Nasir and Cooks (2009) argue for the importance of "ideational resources" in developing and establishing one's identity within a particular learning space (p. 44). Ideational resources might include specific lessons or sayings about how to manage one's emotions in a 
challenging scenario or how to name oneself in relation to others, for instance as a core participant in a community (i.e., a "hurdler" or a "jumper" in track-and-field or a "problem solver" in a CS class). Reflecting on designed artifacts that capture the complexities of CS can be one way to engage students in developing ideational resources.

These ideational resources build on a rich resource in the form of making e-textiles themselves. In the past decade, much research has shown how making e-textiles can encourage personal expression and customization through student projects in ways that are authentically integrated with CS, supporting students' ownership and connections with the field (Buechley, Peppler, Eisenberg, \& Kafai, 2013). In particular the ways e-textiles disrupt traditional gendered boundariescombining the female traditions of crafting with the more male-dominated disciplines of engineering and CS-have led to more women engaging in programming with the microcontroller platform Arduino (Buechley \& Hill, 2010; Bucholtz, Shivley, Peppler \& Wohlwend, 2014). Furthermore, e-textiles can provide multiple points of entry into CS: crafting, electronics, and coding are all legitimate entry points into the activity (Kafai, Fields, \& Searle, 2014). Thus etextiles disrupt not only gender boundaries but also disciplinary boundaries, in addition to class and ethnicity boundaries. For instance, the crafting elements of e-textiles have provided indigenous students (both boys and girls) agency to explore particular aspects of their cultural identities and thus facilitate students' connections between home and school spaces (Kafai, Searle, Martinez, \& Brayboy, 2014; Searle \& Kafai, 2015).

Though creating personalized artifacts linked to core disciplinary content such as e-textiles can support students' identities in practice-based ways (Van Horne \& Bell, 2017), the design process alone may not necessarily help students articulate a clear sense of self (i.e., self-narrative) in relation to a discipline. One of the reasons is that these "narrative identities" as identified by Ezzy (1998) are not only constructed when students interact with others within the discipline; they are also constructed through internal dialogue, supporting the development of a stable sense of self. Activities in which students reflect and share who they are and who they are becoming as computer scientists can provide these more internalized venues for developing self-narratives. Students can reflect on their engagement with CS practices; imagine and represent themselves doing CS in and out of school, as well as now and later in life; and align themselves with CS practices by imagining computer scientists and considering similarities and differences between themselves and these practitioners (Varelas, Martin, \& Kane, 2012). This calls for the incorporation of activities that require students to reflect on their identities in the same way we give them time to reflect on the concepts and practices they are learning, allowing them to leverage their sense of selves with the CS content they are learning (Varelas, Martin, \& Kane, 2012). Portfolios offer an opportunity for students to link their practices in creating computational artifacts like e-textiles with their own developing self-narratives in relation to CS. 


\section{Portfolios as Ideational Resources}

Portfolios have been utilized in many classrooms as culminating artifacts to showcase students' work, accompanying the actual project(s) that students have made (Paulson, Paulson \& Meyer, 1991). For instance, portfolios featuring the best or series of projects students have made highlight students' accumulated competency and skill (Býrgýn \& Baký, 2007). While those kinds of portfolios are commonly found in arts education, they have begun to be utilized more recently in CS education. Portfolios can also be process-based, showing students' progress through a series of projects or even within a project (e.g., Chang et al., 2015). For example, in the Advanced Placement Computer Science Principles course, students are required to submit both a project and a portfolio that showcases the intention behind their project as well as documents how their project was made (College Board, 2017), thereby serving as both a learning assessment and a demonstration of their learning progress. Through this process, students can narrate how they have grown throughout the creation of a single project or across multiple projects, which allows them to author their own pathways of learning through reflection.

We propose that, through this self-narration, portfolios can serve as ideational resources that support students' self-authorship of disciplinary identity (see Van Horne \& Bell, 2017). By letting students reflect on their pathways into CS in relation to the content they are learning, portfolios can alter their perceptions of that field, thereby increasing their sense of belonging. Having a sense of belonging can mean having a relationship with a group of people that brings about a secure feeling of fitting in (Lambert, Stillman, Hicks, Kamble, Baumeister, \& Fincham, 2013), and students' sense of belonging in an academic environment like CS depends on how they feel they would fit in with the people, materials, and activities within that environment (Cheryan, Plaut, Davies, \& Steele, 2009). Below we describe the type of portfolio that our students made in the e-textiles curricular unit, a portfolio that was both project-based (featuring a series of e-textiles artifacts students made) and process-based (highlighting challenges and revisions made in the process of making the projects). We then explore the ways that students expressed and authored themselves in relation to CS through the personalized portfolios that they created. Lastly, we end the paper with a discussion about what it means to identify as a computer scientist, as well as the implications of using meta-artifacts as tools for identity development in educational implementation and constructionist pedagogy.

\section{Methods}

Over the past two years, we have co-developed an e-textiles unit for the Exploring Computer Science curriculum, a year-long course providing an introduction to computing with equity-focused and inquiry-based teaching (Goode et al., 2012). The e-textiles unit took place over eight weeks and consisted of a series of four projects: 
1. a paper-card using a simple circuit;

2. a wristband with three LEDs in parallel;

3. a classroom-wide mural project in which pairs of students created portions that each incorporated two switches to computationally create four lighting patterns; and

4. a "human sensor" project that used two aluminum foil conductive patches that when squeezed generated a range of data to be used as conditions for lighting effects (for more details, see Kafai \& Fields, 2018).

Each project allowed increasing flexibility in design and personalization, and the human sensor projects reflected this in the diversity of students' projects: stuffed animals, paper cranes, wearable shirts or hoodies, handbags, projects featuring students' names or pop culture icons, and gifts for family members.

In the second year of implementation, with the help of the pilot teachers, we revised the unit, adding reflective portfolios as a capstone to accompany the final project of the unit. The portfolio that students created was co-developed with Ben and José, the teachers of the ECS classes that are the subjects of this paper. The portfolio was both project- and process-based, showing one or more projects students made as well as reflections about their processes of making them. The portfolio consisted of a set of at least four Google Slides, with students adding on slides as desired. For each project, the requirements included (a) an initial drawing of the project and a reflection on changes made to the project; (b) at least one challenge they faced and an explanation of how they dealt with it; (c) how they had "grown as a computer scientist," accompanied by at least one picture or video of their work in progress; and (d) a picture/video of the final project with an explanation of what it did plus a reflection about what they learned and how the project fit into their identities as computer scientists. The portfolio ended with one final reflection on all their learning across the entire unit. Students were assessed based on whether their portfolios met the five requirements. Though the portfolio was designed to represent one project (the final project), Ben had his students create a portfolio entry on each of the four projects in the unit, which meant that his students' portfolios were substantially longer.

Figures 1-3 provide examples of how students chose to illustrate the different parts of the portfolio assignment, as well as how students personalized their portfolios. All but one student personalized their portfolios by using specialized fonts and backgrounds, adding title pages for each project, creating digital representations of their projects, and incorporating selfies or images that exhibited their own styles and interests. 


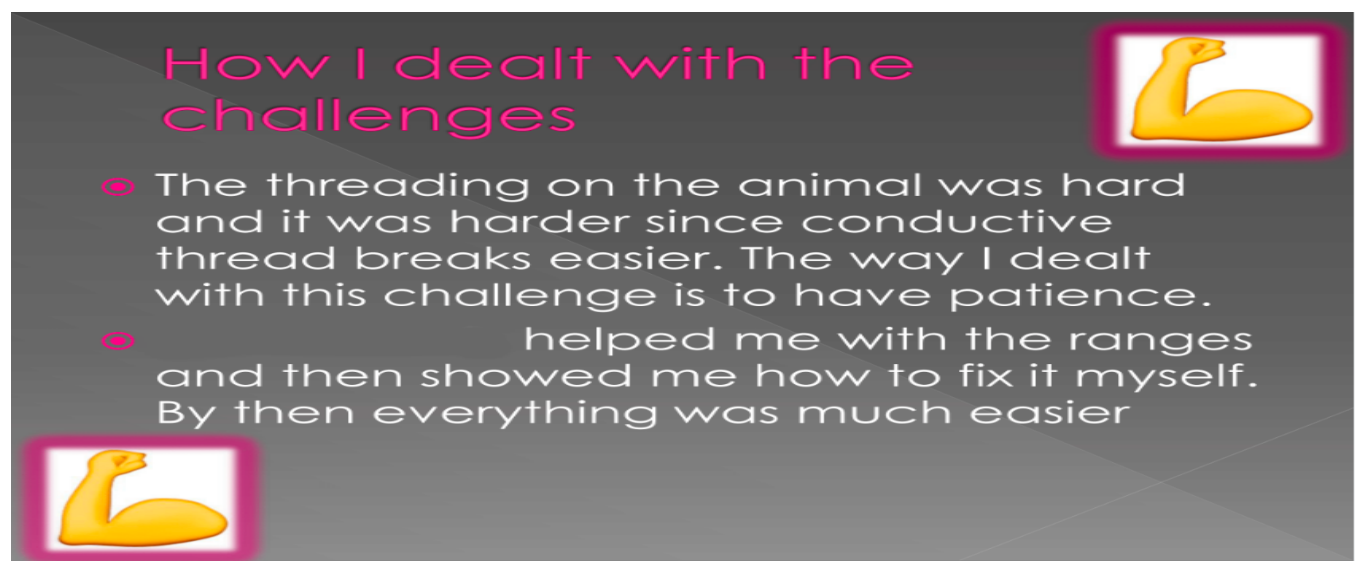

Figure 1. Diana's portfolio page on how she dealt with challenges in her human sensor project.

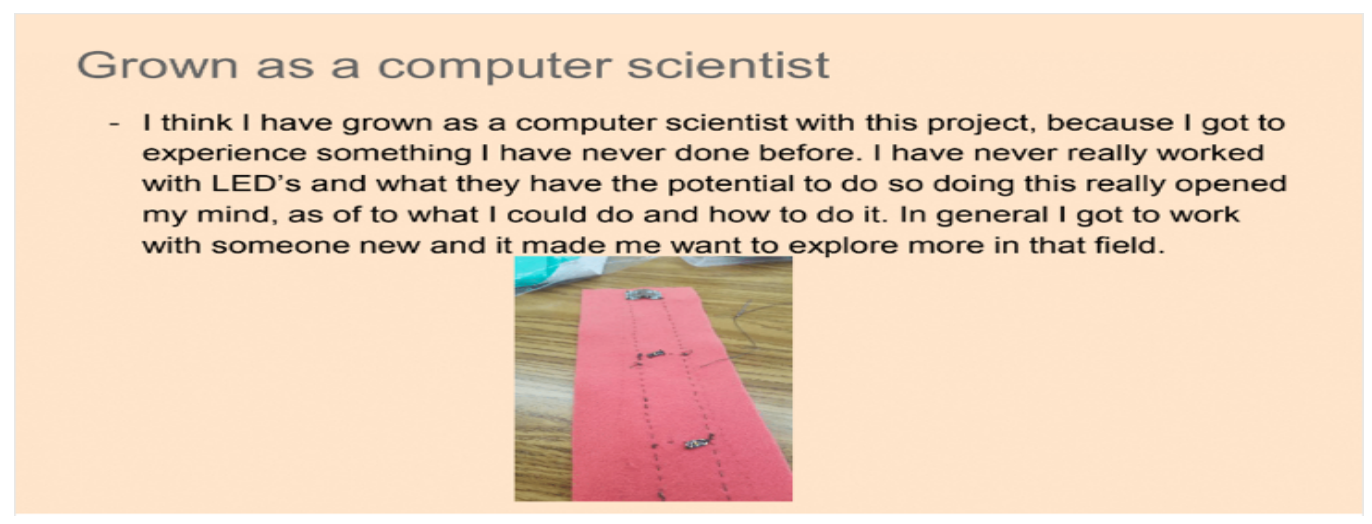

Figure 2. Alejandra's portfolio page on growing as a computer scientist after the wristband project.

\section{Human Sensor Reflection}

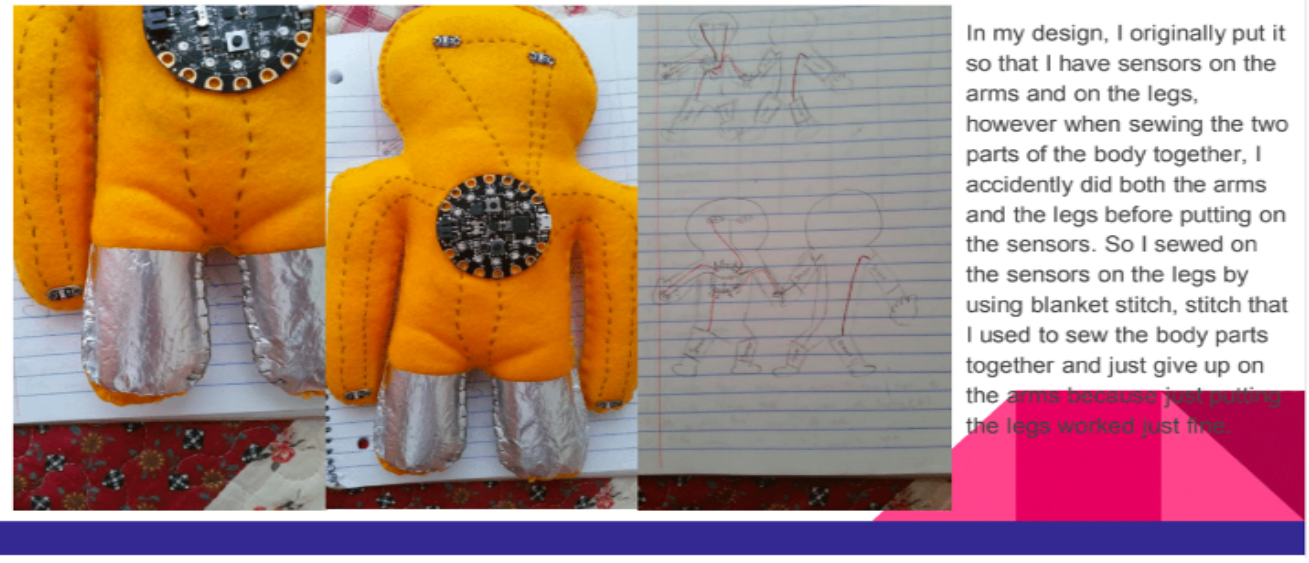

Figure 3. Louis' portfolio page on challenges in the human sensor project. 


\section{Participant Demographics}

Both teachers worked at schools that serve a large number of students who come from ethnic/racial groups that are traditionally underrepresented in CS. Ben piloted the e-textiles unit in Spring 2017 in his ECS class at an independent charter school with 36 students ( 13 girls and 22 boys): 35 consented to participate in the research project, and 34 of those submitted portfolios. Most students were in 9th grade (14-15 years old); one student was in 12th grade (17 years old). At Ben's school, $54 \%$ of students were identified as socioeconomically disadvantaged as defined by the State of California and included the following demographics: $4 \%$ African American, 18\% Asian, 10\% Filipino, 40\% Hispanic or Latino, 25\% White, $1 \%$ as two or more races, and $2 \%$ race not reported. The school had a three-year trajectory of elective CS courses, with ECS being the introductory course.

José taught ECS at a science and math magnet school housed in a larger public high school, with 29 students ( 20 girls, 9 boys): 27 consented to participate in the research project, and 21 of those submitted portfolios. Most students were in 9th grade and were in the honors program at the school. At José's school, $95 \%$ of students were identified as socioeconomically disadvantaged and included the following demographics: 9\% African American, 89\% Hispanic or Latino, and 1\% White. The school has two primary CS courses, ECS and AP Computer Science Principles, with related offerings in animation and robotics.

\section{Data Collection and Analysis}

The data for this project included the digital portfolios from all 55 consenting students who submitted portfolios in Ben and José's classes. For analysis we sought to develop a framework for exploring how students utilized the portfolio assignment to express themselves in relation to the field of CS. We conducted multiple rounds of grounded, comparative analysis (see Charmaz, 2002). We initially developed 11 codes stemming from the identity statements students generated as answers to the question "How have I grown as a computer scientist?" However, we found these codes limiting, as we noticed that students related to and framed CS in more subtle ways outside the identity statements. In a second review of the portfolios, we expanded our analysis to statements throughout the entire portfolio, developing several new categories in addition to the original ones. We also identified ways in which students personalized their portfolios beyond what was required for the assignment, noting their use of fonts, visuals (Internet images, cartoons, or emojis), and photos of themselves. While these examples illustrated ways in which students were able to express themselves creatively in their portfolios, they were not included with the categories we developed due to the lack of direct explanations that would allow us to connect them to students' narrative identities. We created a dictionary of codes with examples for clarity; then two of us independently coded a portion of the portfolios until they reached uniform 
agreement. We then proceeded to code the remaining portfolios separately, soliciting second opinions for borderline areas as needed.

In further analysis, we compared and contrasted the categories of codes, looking at areas of commonality and areas of exception. We also compared results from the two classes, noting where there were similar or different patterns. Finally, we analyzed student narrative statements that did not fit any of our six categories to consider what they revealed about the portfolios, reflection, and student narratives about CS. The discovery of these narrative statements that did not fit within our six categories (for example, how an artifact displayed a student's interest in nature or how a student related to the struggle that gamers experience) illuminated a potential blindspot into how students are conceptualizing their relation to CS. Overall, though, these stages of analysis helped unveil how the portfolios afforded students the space to articulate how they identify with CS. In the end we framed our research in the six broad categories shown in Table 1.

Table 1

Final Coding Categories for Student Portfolios.

\section{Self as Type of Computer Science (CS) Person}

Hard Skills: Students explicitly linked growth as a computer scientist with specific skills they learned, such as sewing, coding, or making circuits.

Problem-Solving: Students called themselves problem-solvers and related this to doing computer science or being a type of computer scientist.

\section{CS as Personal and Relational}

Socioemotional: Students described how doing the project or the project itself demonstrated personal characteristics they held, such as dedication, perseverance, patience, getting out of one's comfort zone, making mistakes, or collaborating with others.

Relational: Students expressed a relationship with a friend, family member, or teacher that either provided feedback on the e-textile project, involved collaboration, or made a project intended for someone else.

\section{Self and the CS Field at Large}

Future Intentions: Students discussed themselves in a future tense in relation to computer science in the context of applications outside the classroom such as future jobs or in other projects.

New Realizations: Students described new realizations of what computer science is or what it can include. 


\section{Findings}

As students deepened their participation in CS practices through the creation of their e-textiles artifacts, their portfolios served as ideational resources that illustrated students' reflection and active construction of their CS identities (Wenger, 1988; Nasir \& Cooks, 2009). Throughout our analysis across students' portfolios of the narrative statements within their challenges, how they had "grown as a computer scientist," and unit reflections, we discovered that the portfolios had afforded students the space to develop their own narratives about CS and their place in the field. In developing their portfolios, students not only articulated who they were in relation to CS but identified the various resources, skills, and personal qualities that had helped them construct their artifacts. In addition, the portfolios allowed students to author new and expanded understandings of CS as a field. They also permitted students to narrate who they could be in the future in relation to CS, expressing an interest in CS beyond this unit.

\section{Identifying as Types of Computer Scientists}

Students linked themselves with computer science through specific functional skills they had learned that they believed aligned with being a computer scientist. In total, 34 students said that they had grown as a computer scientist through developing specific skills: 28 of these students listed specific coding skills, 15 cited circuitry skills, and 9 mentioned crafting skills (some students cited multiple skills across their portfolios). For instance, Diana claimed, "This product...fits me into the category of a computer scientist because it had programming involved and you really try different things with programming as a Computer Scientist." Here Diana explicitly connected her skills used in making her e-textiles "product" with being a computer scientist. The frequency of students linking being a computer scientist with particular skills is striking and shows the association they made between being a computer scientist and the practices that they learned in class while creating projects-seeing a direct link between what they were doing and who they were as computer scientists, thereby developing self-narratives in relation to CS (Varelas, Martin, \& Kane, 2012).

We also found a few times when this appeared to work against students' identification with CS, in that students associated themselves more conditionally with CS because of a perceived lack of skills. As an example, Cristian wrote, "To me I think I'm not a computer scientist right now because I'm not that good in coding, but if I practice and get better I think I can become a computer scientist." Because he associated the skill of coding with being a computer scientist, Cristian leveraged his sense of self as a computer scientist with the CS content he was learning (Varelas, Martin, \& Kane, 2012), thereby not identifying as a computer 
scientist but self-narrating that he could become one with more practice. Only a few students exhibited this complicated identification with CS in their portfolios.

This direct link between doing and being is also visible in the ways that students associated being a computer scientist with problem solving. In all, 22 students authored themselves as problem solvers specifically in relation to CS. Jarvis expressed this the most obviously; he wrote: "This has definitely helped me as a computer scientist as a lot of CS is problem solving." In this, Jarvis made a direct statement that CS is problem solving, and since he did some problem solving in his work, he therefore was a computer scientist in the making. Other students explained this connection between being a computer scientist and problem solving as "realizing my mistakes so I do not make the same mistakes the next time" (Jeevan), or saying, "Because of the fact that we have to figure out the programs and see why things aren't working it helps you and makes you see what CS is about" (Alanna). This connection between problem solving and identity is intriguing because problem solving is a more general skill or way of thinking than particular skills of coding (as discussed above), crafting, or making circuits. In other analyses we found that students' highlighting how to problem solve or work through challenges reflected broader, intentional teaching practices of classroom communities that value mistakes and failure as legitimate means of learning (see Fields et al., 2018). This suggests a need to look more deeply at classroom discourse and practice, studying how those actions shaped what kinds of associations students made with CS, and why certain students developed more tenuous associations with CS.

In positioning themselves as having new skills in CS as well as abilities in problem solving, these high school students challenged the common notion of not being "smart enough" to participate in CS (Yardi \& Bruckman, 2007). In other words, as opposed to being told what computer scientists do or what kinds of people they are (which can act as a barrier for participation in CS), the students personally altered stereotypes and broadened what computer scientists look like, making space for themselves and their belonging within that field.

\section{Relating to Computer Science as Personal and Social}

Beyond listing particular skills and practices, 24 students also linked socioemotional characteristics to being computer scientists. Consider Ashley's explanation about being creative and taking risks: "This project fits into my identity of a computer scientist because it allows me to go out of my comfort zone and create something new. Creating doesn't only mean put everything together, but it also means to imagine, discuss, evaluate, and understand." Here, Ashley explored an expanding view of creativity with her willingness to step out of her comfort zone as important personal attributes she associated with being a computer scientist. Other students expressed how they felt "more capable" (Heidi), how "I dealt with problems by having patience" (Nadia), or how the process of making e-textiles demonstrated that "hard work pays off" (Chuy). For these students, CS was more 
than just learning specific skills or coding; instead, they connected CS to personal attributes that they valued. Some of these were expressions of attributes that students already had, allowing students to connect treasured parts of their personalities to CS, such as creativity, independence, or dedication. Others were new characteristics that students claimed they learned over the course of finishing projects, such as patience, perseverance, or innate capability.

In addition, students particularly challenged the stereotypical perception of CS as being antisocial (Yardi \& Bruckman, 2007). In total, 30 students mentioned relationships as serving a role in the construction of their artifacts, whether it was by working with a partner on the mural project, gaining help from their peers or the teacher, or eliciting feedback from peers or family members. Heidi, for example, came up with her project idea by eliciting feedback from both her mother and her peers: "Unfortunately my mom didn't want me to sew one of my pants, so it was between a corgi pattern or the flowers. Many people wanted the flowers so eventually I decided to do flowers on the bag." In other words, Heidi valued people's opinions in her design process, truly conceptualizing her e-textile project as an "object-to-share-with" (Kafai \& Burke, 2014). Four other students specifically designed their e-textiles artifacts as gifts for family members, integrating relationships in the purpose of their designs. For example, both Jeremy and Ana designed their electronic cards for their mothers, while Ashley and Sara designed their human sensor projects (a ladybug and a wolf, respectively) for their little sisters. Designing their projects for family members and leveraging those relationships created additional meaning and relevance for students in considering the role CS plays in their lives.

What is equally noteworthy and relevant about students mentioning how relationships played a role in their projects is the fact that most of their projects (aside from the mural project) and their portfolios were individual assignments. However, in reflecting on their learning through their portfolios, over half of the students recognized how others played a role in their being able to construct their projects, serving as relational resources and demonstrating how without explicit prompting they were able to author an expanded understanding of computing as a social field. Yolanda ensured that other people were woven into the very fabric of her project: "My project shows that I am thankful for the people that have supported me throughout this long journey. I always try to include people I love into what I'm doing." This made the e-textiles unit a connective space where collaboration and relationships with others were valued in the process and products of the unit. By acknowledging the social aspects of CS, students who normally view the field as antisocial (Yardi \& Bruckman, 2007) can develop an increased interest and sense of belonging, such as Alejandra who stated, "In general I got to work with someone new and it made me want to explore more in that field." These social dimensions in students' reflections illustrate most poignantly what we mean by "computational participation" (Kafai \& Burke, 2014) that puts computational thinking into a social context. 


\section{Situating Selves with Computer Science as a Field}

The portfolios also afforded students the space to author new and expanded understandings of CS as a field. In analyzing all of the portfolios, we found that 24 students described new realizations of what CS is outside the classroom and how relevant it was to them personally. For example, students expressed increased passion about CS, including Martha who shared "how interesting it is to be a computer scientist." Students also saw new relevance for computing in objects around them, including Kevin who learned that "there is coding in everything." Furthermore, students shared discovering new ways that CS is done. For instance, as opposed to CS being a highly regimented field with limited ways to participate, Adeep reflected how "this project... helped me grow as a computer scientist by showing me that CS does not have some sort of a handbook." It should be noted that students were not required to reflect on CS as a field. However, in reflecting on their identities as computer scientists, students positioned themselves in the field by broadening its criteria in ways that validated their participation. In addition, they reflected on how what they did in completing their projects related to how CS is done in the real world, which speaks to how they were able to create meaning and relevance from their projects. By developing and maintaining meaningful narratives related to $C S$ through their portfolios, students were able to identify more closely with the field (Ezzy, 1988).

Other students, 15 in all, authored themselves as participating in e-textiles projects in the future, including Shona who expressed interest in doing "both of these projects again due to the wonderful experiences I have gathered." In addition to wanting to make e-textiles in the future, students like Leon and Ashley identified specific lessons they learned from the projects that they would apply for future etextiles projects, such as listening more carefully in order to make fewer mistakes (Leon) or creating an initial plan before designing (Ashley). By identifying these lessons, they were given the opportunity to use their portfolios as ideational resources to reflect on how they could improve upon their initial designs and experiences, increasing their chances of success. Students like Jesse expressed interest in exploring CS beyond the e-textiles class, particularly in college. These examples illustrate how portfolios afford students the opportunity to develop positive self-narratives that situate them on an inbound trajectory of participation in CS.

\section{Discussion}

All in all, we argue that these reflective portfolios can serve as ideational resources that provide an explicit means for students to construct self-narratives in relation to CS. First, the portfolios show a progression of time in which students shared their project development with e-textiles, challenges they conquered, lessons they learned, and occasionally a projection into the future of themselves 
doing CS in some way. Second, students actively connected other aspects of themselves into these narratives, including personal characteristics like creativity or independence and personal relationships with family, friends, and teachers. Elsewhere we have noted how personal relevance and relationships are embodied directly into the e-textile artifacts students create (Kafai, Fields \& Searle, 2014; Searle, Fields, Lui, \& Kafai, 2014). In those artifacts the students saw how their struggles, newly-developed knowledge, and relationships were present, but these were not necessarily viewable to others without verbal interpretation. In the portfolios, however, students provided more explicit narrative accounts of struggle, help, learning, relationships, developed knowledge, personal values, and future projections.

In the remaining section we discuss how we see portfolios as ideational resources for fostering more equitable connections, for creating spaces for communicating about understandings of CS, and potentially for developing critical identities. Finally, we discuss equitable teaching practices that can support narrative development in portfolios.

In the discipline of computer science, a discipline that is well-documented for leaving out important multicultural education features like identity, diversity, community, and culture (Scott, Sheridan, \& Clark, 2014), reflective, process-based portfolios may provide a means to support students in consciously developing personally relevant narratives that link them to broader CS communities. By connecting aspects like personal, socioemotional characteristics and relationships with others into their self-narratives, students in our study authored CS identities that expanded what it means to identify with that discipline. While disciplinary identification research has focused on how students coordinate their multiple identities and engage in practices in relation to a specific discipline (Bell, Van Horne, \& Cheng, 2017), students' self-narratives not only authored an understanding of CS as a social field but leveraged these relationships as expanded ways to identify with CS. Furthermore, our students expanded what it means to be a competent computer scientist beyond the functional practices of coding, crafting, and circuitry to socioemotional skills such as perseverance and patience, thereby linking their disciplinary identity not only to specific skills but also to valued personal characteristics.

Meanwhile, as part of the negotiation of identities within a place of practice, in their portfolios students simultaneously created CS as a space where (mostly) they belonged. They associated it with skills and knowledge from their projects, discourses about problem solving, and values of patience and perseverance. Furthermore, contrary to prominent stereotypes about CS, they described it as a creative and collaborative space where people like them (of varying genders, ethnicities, and classes) could participate. This space was directly related to what they made, how their artifact reflected their growing understanding of what CS is, and the types of experiences they had in an equity-oriented e-textiles ECS classroom (Lui, Jayathirtha, Fields, Shaw, \& Kafai, 2018; Goode, Chapman \& Margolis, 2012). 
One other positive aspect of the portfolios is that they also demonstrated student learning. Though we have explored this aspect less in this paper, the original intention behind the portfolios was to show students' learning of challenging computational thinking skills in problem solving and debugging (Lui, Jayathirtha, Fields, Shaw, \& Kafai, 2018). In other words, the process-oriented design of the portfolios supported both personal narrative development and expression of process-based thinking skills. Further, students not only learned to express themselves personally but also learned to communicate about CS, something regarded as an essential computational thinking practice (College Board, 2017; Lui, Jayathirtha, Fields, Shaw, \& Kafai, 2018). Altogether, we believe this shows the potential for reflective portfolios to be powerful accompaniments to artifact-development. They can serve as a means to assess process-based computational thinking, to help students learn to communicate within the discipline of CS, and to develop self-narratives that support disciplinary identification with CS. These three aspects support each other, and the representation and communication of learning reinforces narratives about belonging in a CS discipline.

While prior research on e-textiles has highlighted the cultural responsiveness of e-textiles in addressing the identity gap of underrepresented students within computing (e.g., Native American youth, Searle \& Kafai, 2015), facilitating more conscious identity work through reflection has been largely absent. This paper demonstrates the potential in using process-based portfolios to support students in consciously reflecting on their identities and developing narratives relating who they are and what they are learning regarding computer science. However, learning with portfolios could go even further. Even though the portfolios in this project implicitly allowed for more equitable identifications with CS for students through self-narratives and the altering of CS stereotypes, one thing they did not do is engage students explicitly in articulating who they are in relation to CS in terms of their gender, ethnicity, or other social identities. One of the tenets of culturally responsive computing is that "technology should be a vehicle by which students reflect and demonstrate understanding of their intersectional identities" (Scott, Sheridan, \& Clark, 2015, p. 421). Further studies could explore the potential of portfolios for students to author deeper self-narratives that not only allow reflection on their disciplinary identities with their intersectional identities using explicit questioning but also intentionally address how these authored identities challenge the aspects of CS that exclude underrepresented groups. Research on CS classroom practice and discourse connected with student outcomes such as portfolios would be a productive direction for future studies concerned with pedagogy and identity as this discipline continues to develop in K-12 education.

\section{Acknowledgements}

An earlier, partial version of this analysis was presented at the Constructionism 2018 conference by the authors. This research was supported by a grant \#1509245 from the National Science Foundation to Yasmin Kafai, Jane Margolis, 
and Joanna Goode. Any opinions, findings, and conclusions or recommendations expressed in this paper are those of the authors and do not necessarily reflect the views of the National Science Foundation, the University of Pennsylvania, or Utah State University. Special thanks to Tomoko Nakajima, Debora Lui, Justice Walker, and Gayithri Jayathirtha for their help with data collection, portfolio design, and constructive feedback.

\section{Notes}

1. All names of research participants, including teachers, students, and schools, are pseudonyms.

2. One researcher personally introduced the study to each class, providing opportunities for students to assent and for their parents to consent to their participation in the research study. She made it clear that students could do the e-textile unit regardless of their participation in the research and that any results would be reported anonymously. Further, students and parents provided additional explicit consent for images of their projects or quotes from their interviews to be used in research papers and presentations.

\section{References}

Bell, P., Van Horne, K., \& Cheng, B. (2017). Special issue: Designing learning environments for equitable disciplinary identification. Journal of the Learning Sciences, 26(3), 367-375.

Blikstein, P. (2018). Pre-college computer science education: A survey of the field. Mountain View, CA: Google LLC. Retrieved from https://goo.gl/gmS1Vm

Buechley, L. (2006). A construction kit for electronic textiles. Proceedings from IEEE '06: The Tenth IEEE International Symposium on Wearable Computers. Montreux, Switzerland: IEEE.

Buechley, L., \& Hill, B. (2010). LilyPad in the wild: How hardware's long tail is supporting new engineering and design communities. Proceedings from DIS 10: The Eighth ACM Conference on Designing Interactive Systems. Aarhus, Denmark: ACM.

Buechley, L., Peppler, K., Eisenberg, M., \& Kafai, Y. (Eds). (2013). Textile messages: Dispatches from the world of e-textiles and education (New literacies and digital epistemologies). New York, NY: Peter Lang.

Buchholz, B., Shively, K., Peppler, K., \& Wohlwend, K. (2014). Hands on, hands off: Gendered access in crafting and electronics practices. Mind, Culture, and Activity, 21(4), 278-297.

Býrgýn, O., \& Baký, A. (2007). The use of portfolio to assess students' performance. Journal of Turkish Science Education, 4(2), 75-90. 
Chang, S., Keune, A., Peppler, K., Maltese, A., McKay, C. \& Regalla, L. (2015). Open portfolios: Maker education initiative full research brief series. Retrieved from http://makered.org/opp/publications/

Charmaz, K. (2002). Stories and silences: Disclosures and self in chronic illness. Qualitative Inquiry, 8(3), 302-328.

Cheryan, S., Plaut, V., Davies, P., Steele, C. (2009). Ambient belonging: How stereotypical cues impact gender participation in computer science. Journal of Personality and Social Psychology, 97(6), 1045-60.

Cheryan, S., Plaut, V., Handron, C., \& Hudson, L. (2013). The stereotypical computer scientist: Gendered media representations as a barrier to inclusion for women. Sex Roles, 69(1-2), 58-71.

Cheryan, S., Master, A., \& Meltzoff, A. (2015). Cultural stereotypes as gatekeepers: Increasing girls' interest in computer science and engineering by diversifying stereotypes. Frontiers in Psychology, 6(49), 1-8.

College Board (2017). Advanced placement computer science principles course guide. Retrieved from https://apcentral.collegeboard.org/pdf/ap-computerscience-principles-course-and-exam- description.pdf

Diekman, A., Brown, E., Johnston, A., \& Clark, E. (2010). Seeking congruity between goals and roles: A new look at why women opt out of STEM careers. Psychological Science, 21(8), 1051-1057.

Eglash, R., Gilbert, J., \& Foster, E. (2013). Broadening participation: Toward culturally responsive computing education. Communications of the ACM, 56(7), 33-36.

Ezzy, D. (1988). Theorizing narrative identity. The Sociological Quarterly, 39(2), 239-252.

Fields, D., \& Enyedy, N. (2013). Picking up the mantle of "expert": Assigned roles, assertion of identity, and peer recognition within a programming class. Mind, Culture, and Activity: An International Journal, 20(2), 113-131.

Fields, D., Kafai, Y., Nakajima, T., Goode, J., \& Margolis, J. (2018). Putting making into high school computer science classrooms: Promoting equity in teaching and learning with electronic textiles in "Exploring Computer Science." Equity \& Excellence in Education, 51 (1), 21-35

Good, C., Rattan, A., \& Dweck, C. (2012). Why do women opt out? Sense of belonging and women's representation in mathematics. Journal of Personality and Social Psychology, 102(4), 700-717.

Goode, J., Chapman, G., \& Margolis, J. (2012). Beyond curriculum: The Exploring Computer Science program. ACM Inroads, 3(2), 47-53.

Google Inc., \& Gallup Inc. (2016). Diversity gaps in computer science: Exploring the underrepresentation of girls, Blacks and Hispanics. Retrieved from http://goo.gl/PG34aH 
Hansen, A. K., Dwyer, H. A., Iveland, A., Talesfore, M., Wright, L., Harlow, D. B., \& Franklin, D. (2017). Assessing children's understanding of the work of computer scientists: The draw-a-computer-scientist test. Proceedings from SIGCSE '17: The 2017 ACM SIGCSE Technical Symposium on Computer Science Education. New York, NY: ACM.

Kafai, Y. \& Burke, Q. (2014). Connected code: Why children need to learn programming. Cambridge, MA: The MIT Press.

Kafai, Y., Fields, D., \& Searle, K. (2014). Electronic textiles as disruptive designs: Supporting and challenging maker activities in schools. Harvard Education Review, 84(4), 532-556.

Kafai, Y., Searle, K., Martinez, C., \& Brayboy, B. (2014). Ethnocomputing with electronic textiles: Culturally responsive open design to broaden participation in computing in American Indian youth and communities. Proceedings from SIGCSE '14: The Forty-fifth ACM Technical Symposium on Computer Science Education. Atlanta, GA: ACM.

Kafai, Y., \& Fields, D. (2018). Some reflections on designing constructionist activities for classrooms. Proceedings from Constructionism 2018. Vilnius, Lithuania.

Lambert, N., Stillman, T., Hicks, J., Kamble, S., Baumeister, R. \& Fincham, F. (2013). To belong is to matter: Sense of belonging enhances meaning in life. Personality and Social Psychology Bulletin, 39(11), 1418-1427.

Leslie, S., Cimpian, A., Meyer, M., \& Freeland, E. (2015). Expectations of brilliance underlie gender distributions across academic disciplines. Science, 347(6219), 262-265.

Lui, D., Jayathirtha, G., Fields, D., Shaw, M., \& Kafai, Y. (2018). Design considerations for capturing computational thinking practices in high school students' electronic textile portfolios. Proceedings from ICLS '18: The Thirteenth International Conference on the Learning Sciences. London, UK: ISLS.

Margolis, J., Estrella, R., Goode, J., Jellison Holme, J., \& Nao, K. (2008). Stuck in the shallow end: Education, race and computing. Cambridge, MA: MIT Press.

Nasir, N. S., \& Hand, V. (2008). From the court to the classroom: Opportunities for engagement, learning, and identity in basketball and classroom mathematics. Journal of the Learning Sciences, 17, 143-179.

Nasir, N., \& Cooks, J. (2009). Becoming a hurdler: How learning settings afford identities. Anthropology \& Education Quarterly, 40(1), 41-61.

Paulson, F., Paulson, P., \& Meyer, C. (1991). What makes a portfolio a portfolio. Educational Leadership, 48(5), 60-63.

Pinkard, N., Erete, S., Martin, C., \& McKinney de Royston, M. (2017). Digital youth divas: Exploring narrative-driven curriculum to spark middle school girls' 
interest in computational activities. Journal of the Learning Sciences, 26(3), 477-516.

Renninger, K. A. (2009). Interest and identity development in instruction: An inductive model. Educational Psychologist, 44(2), 105-118.

Scott, K., Sheridan, K., \& Clark, K. (2015). Culturally responsive computing: A theory revisited. Learning, Media and Technology, 40(4), 412-436.

Searle, K., Fields, D. A., Lui, D. \& Kafai, Y. B. (2014). Diversifying high school students' views about computing with electronic textiles. Proceedings from ICER '14: The Tenth Annual Conference on International Computing Education Research. New York, NY: ACM.

Searle, K., \& Kafai, Y. (2015). Boys' needlework: Understanding gendered and indigenous perspectives on computing and crafting with electronic textiles. Proceedings from ICER '15: The Eleventh Annual International Conference on International Computing Education Research. Omaha, Nebraska: ICER.

Searle, K., \& Kafai, Y. (2015). Culturally responsive making with American Indian girls: Bridging the identity gap in crafting and computing with electronic textiles. Proceedings from GenderlT '15: The Third Conference on GenderIT. Philadelphia, PA: GenderIT.

Sfard, A., \& Prusak, A. (2005). Telling identities: In search of an analytic tool for investigating learning as a culturally shaped activity. Educational Researcher, 34 (4), 14-22.

Smith, J., Lewis, K., Hawthorne, L., \& Hodges, S. (2013). When trying hard isn't natural: Women's belonging with and motivation for male-dominated STEM fields as a function of effort expenditure concerns. Personality and Social Psychology Bulletin, 39(2), 131-143.

Tai, R., Liu, C., Maltese, A. \& Fan, X. (2006). Planning early for careers in science. Science, 312(5777), 1143-1144.

Van Horne, K., \& Bell, P. (2017). Youth disciplinary identification during participation in contemporary project-based science investigations in school. Journal of the Learning Sciences, 26(3), 437-476.

Varelas, M., Martin, D., \& Kane, J. (2012). Content learning and identity construction: A framework to strengthen African American students' mathematics and science learning in urban elementary schools. Human Development, 55(5-6), 319-339.

Wenger, E. (1998). Communities of practice: Learning, meaning, and identity. Cambridge, UK: Cambridge University Press.

Yardi, S., \& Bruckman, A. (2007). What is computing? Bridging the gap between teenagers' perceptions and graduate students' experiences. Proceedings from ICER '07: The Third International Workshop on Computing Education Research. New York, NY: ACM. 


\section{Author Contact}

Mia S. Shaw, mshaw12@gse.upenn.edu

Graduate School of Education, University of Pennsylvania, 3700 Walnut Street, Philadelphia PA 19104, U.S.A.

Deborah A. Fields, deborah.fields@usu.edu

Utah State University, 2830 Old Main Hill, Logan, UT, 84322, U.S.A.

Yasmin B. Kafai, kafai@upenn.edu

Graduate School of Education, University of Pennsylvania, 3700 Walnut Street, Philadelphia PA 19104, U.S.A. 